\title{
In-Silico Drug Designing of Spike Receptor with Its ACE2 Receptor and Nsp10/Nsp16 MTase Complex Against SARS-CoV-2
}

\author{
M A. Siddiqa ${ }^{1}$ - D. S. Rao ${ }^{1} \cdot$ G. Suvarna ${ }^{2}$ - V. K. Chennamachetty ${ }^{3}$ M. K. Verma ${ }^{4}$ M. V. R. Rao ${ }^{5}$
}

Accepted: 2 March 2021 / Published online: 17 March 2021

(c) The Author(s), under exclusive licence to Springer Nature B.V. 2021

\begin{abstract}
The realm Riboviria constitutes Coronaviruses, which led to the emergence of the pandemic COVID 19 in the twenty-first century affected millions of lives. At present, the management of COVID 19 largely depends on antiviral therapeutics along with the anti-inflammatory drug. The vaccine is under the final clinical phase, and emergency use is available. We aim at ACE2 and Nsp10/Nsp16 MTase as potential drug candidate in COVID 19 management in the present work. For drug designing, various computational simulation strategies have been employed like Swiss-Model, Hawk Dock, HDOCK, py Dock, and PockDrug for homology modeling, binding energies of the molecule with a target, simulate the conformation and binding poses, statistics of protein lock with target key and drug ability, respectively. The current in-silico screening depicts that the spike protein receptor is complementary to the target when bound to each other and forms a stable complex. The MMGBSA free energy binding property of receptor and ligand is critical. The intermolecular Statistics with the target Nsp10/Nsp16 MTase complex are plausible. We have also observed a high-affinity pocket binding site with the target. Therefore, the favorable intermolecular interactions and Physico-chemical properties emanate as a drug candidate treating COVID-19. This study has approached computational tools to analyze the conformation, binding affinity, and drug ability of receptor-ligand. Thus, the spike receptor with its ACE2 receptor with Nsp10/Nsp16 MTase complex would be a potent drug against SARS $\mathrm{CoV}-2$ and can cure the infection as per consensus scoring.
\end{abstract}

Keywords Molecular docking $\cdot$ Molecular dynamics $\cdot$ Nsp10/Nsp16 complex $\cdot$ Spike protein $\cdot$ Scoring functions

$\begin{array}{lll}\text { Abbreviations } & & \text { CAPRI } \\ \text { ACE2 } & \text { Angiotensin converting enzyme 2 } & \\ \text { SARS-CoV-2 } & \begin{array}{l}\text { Severe acute respiratory syndrome-corona } \\ \text { virus 2 }\end{array} & \text { MTase } \\ \text { MERS } & \text { Middle east respiratory syndrome } & \\ \text { SARS } & \begin{array}{l}\text { Severe acute respiratory syndrome } \\ \text { MM/GBSA }\end{array} & \begin{array}{l}\text { Molecular mechanics generalized born } \\ \text { surface area }\end{array} \\ & \end{array}$

Critical Assessment of PRediction of Interactions

ACE2 Angiotensin converting enzyme 2

Severe acute respiratory syndrome-corona

Non-structural protein Nsp10/Nsp 16 methyltransferases

M. V. R. Rao

reachdrmvrrao@gmail.com

M A. Siddiqa

aliza.md9@gmail.com

D. S. Rao

srine.rao@gmail.com

G. Suvarna

g.suvarna@gmail.com

V. K. Chennamachetty drvizae@gmail.com

M. K. Verma mahendra.verma@ausoma.org
1 Department of Biotechnological, Acharya Nagarjuna University, Guntur, Andhra Pradesh, India

2 Department of Biotechnology, Yogi Vemana University, Kadapa, Andhra Pradesh, India

3 Department of Pulmonary Medicine, Apollo Institute of Medical Science and Research, Hyderabad, TS, India

4 American University School of Medicine, Oranjestad, Aruba

5 Scientist-Emeritus and Director of Central Research Laboratory, Department of Laboratory Medicine, Apollo Institute of Medical Sciences and Research, Hyderabad, TS, India 


\section{Introduction}

In December 2019 the first COVID 19 outbreak reported in Wuhan, China as mysterious and contagious viral infection leading to viral pneumonia (Bello 2020). The causative agent for COVID 19 was identified as novel severe acute respiratory syndrome corona virus 2 (SARS-CoV2). The corona viruses are non-segmented RNA viruses generally infect animals precisely wild animal however a few strain are also reported in human as well (Chellapandi and Saranya 2020). Later, a new virus and plague was explored then by WHO as virus pandemic because of the severity of spread at an alarming level in March 2020. COVID-19 is now a pandemic influencing many countries globally (Chen et al. 2020). Coronaviruses are a broad family of viruses which may lead to illness in humans. In humans, several Corona Viruses cause respiratory diseases covering from the common cold to more stringent diseases such as Middle East Respiratory Syndrome (MERS) and Severe Acute Respiratory Syndrome (SARS) (Xu et al. 2020). Both, vaccines and therapeutics are under trials worldwide to prevent and treatment of COVID 19 (Choudhary et al. 2020). There are growing evidences suggesting viral infections often modulate host defense via immune regulation (Verma and Shakya 2020).

\section{SARS-CoV-2 Spike Protein with ACE2 Receptor}

SARS-CoV-2 is extracellular with protein-coat surrounded by a core containing nucleic acid. It is $50-200 \mathrm{~nm}$ in diameter. SARS-CoV-2 includes four structural proteins, referred to as the $\mathrm{S}$ (spike), $\mathrm{E}$ (envelope), $\mathrm{M}$ (membrane), and $\mathrm{N}$ (nucleocapsid) proteins (Ahmad et al. 2020). The genome of the Coronavirus encodes a range of structural proteins that facilitate cellular entry and assembly of virions, of that the spike protein $S$ turns out to be crucial for cellular entry (Alazmi and Motwalli 2020). The spike protein regulates the virus to adhere to the host cell. S protein has within a receptor viz., Receptor Binding Domain. The RBD of spike protein $\mathrm{S}$ binds to Angiotensin-converting protein two (ACE2) to trigger cellular entry (Albini et al. 2020). The spike protein reveals the cleavage sites to cellular proteases when bound to the ACE2 receptor. Subsequently, after the cleavage of spike protein by transmembrane protease serine 2(TMPRSS2) and varied cellular proteases starts fusion and endocytosis (Baig et al. 2020). The spike protein contains addendum furin cleavage site and that will endorse it to be reactivated to gain access to intrude in the cell and vigorously infect once replication starts (Davidson et al. 2020).

\section{Nsp10/Nsp16 Protein}

Structure of Nsp10.The SARS-CoV-2 Nsp10 structure comprises 19-133 residues. An electropositive hydrophobic surface interacts with an electronegative hydrophobic pocket from Nsp16, which contribute the stabilization of the SAM binding site (Donoghue et al. 2020). Structure of Nsp16. Nsp16 structure has all 298 residues. The structure of Nsp16 involves the 2-O-MTase chemical action core composed of a Rossmann-like $\beta$-sheet fold formed by $\alpha$-helices(11), b-strands(7), and loops. The chemical action core requires one molecule of SAM (near the $\beta 1$ and $\beta 2$ strands of the Rossmann-like fold). In eukaryotes, many viruses that replicate inside the substance that has developed $2^{\prime}$ - $O$-methyltransferases (2'-O-MTase) to switch their mRNAs and carry a cap-1 structure (m7GpppNm) at the $5^{\prime}$ end. Similarly, Nsp10 is the stimulatory entity for Nsp16 (El Hassab et al. 2020). This is helpful in SAM-binding pocket and enhancing the substrate RNA-binding groove of nsp16. Intervention by tiny peptides between nsp10 and nsp16 of SARS$\mathrm{CoV}$ may inhibit the activity of $2^{\prime}-O$-MTase. Moreover, the $5^{\prime}$ cap structures of organism mRNAs are crucial for RNA stability and protein translation (Gorbalenya et al. 2020). Thereby aiding infectious agent (viral) replication and escaping innate immune recognition in host cells. The study was aimed to explore 3D structure of drug and target along with desirable functional properties for affinity of drug towards receptor (Guo et al. 2020). We performed molecular modeling, docking and simulation studies for drug receptor interaction and affinity.

\section{Materials and Methods}

\section{Dataset Collection}

The structure of novel coronavirus spike receptor-binding domain complexes with its receptor ACE 2 (protein1) obtained from Protein Data Bank (www.rcsb.org) with PDB ID: 6LZG (Hamming et al. 2004). The target (protein2) viz, room temperature structure of sars-cov-2 Nsp10/Nsp16 methyl-transferase in a complex with sam determined by fixed-target serial crystallography with PDB ID: 6XKM. The protein sequence is retrieved from Uniprot KB (www.unipr ot.org) bearing Uniprot Id: P0DTC2 (SPIKE_SARS2) (Hoffman et al. 2020). The protein sequence of target is retrieved from Uniprot Id: P0DTD1 (R1AB_SARS2) was collected.

\section{Swiss-Model}

A computational tool which relies on the principles from known protein structure/unknown protein sequence. The 
model is obtained via X-Ray diffraction (Hussein et al. 2015). The template selection, alignment and model building as well are automated by the server. It generates a reliable three-dimensional protein structure. It compares target-template giving GMQE, QMEAN (https://swiss model.expasy.org/).

\section{HawkDock}

A network server to predict and analyze the structures of protein-protein complexes basing on computational docking and MM/GBSA (Molecular mechanics generalized born surface area) (Kaswa and Govender 2004). MM/GBSA is a high-throughput virtual screening method widely used to predict binding free energies and to identify the correct binding conformations in the protein-protein complex (http://cadd.zju.edu.cn/hawkdock/).

\section{HDOCK}

It is based on a hybrid algorithm which is template-based modeling and ab-initio docking. The prognosis is topranked performed docking server when submitted the CAPRI experiments (Krishnan et al. 2020). It is highly integrated suite supports intrinsic scoring function with Protein/DNA-RNA docking (http://hdock.phys.hust.edu. $\mathrm{cn} /)$.

\section{pyDock}

A classic approach to the scoring of rigid-body docking poses with FTT based algorithm, which has been implemented in a program pyDock (Lai et al. 2020). The program is based on Columbic electrostatics along with distance-dependent dielectric constant, desolvation and Van Der Waal energy are the molecular dynamics integrated along with protein-protein binding (Letko et al. 2020) https://life.bsc.es/pid/pydock/.

\section{PockDrug}

PockDrug-Server authorizes to predict drug ability probability for a protein pocket in the interest of target recognition aspect of drug discovery ( $\mathrm{Li}$ et al. 2005, 2020). The drug ability of pockets is predicted on holo and apo-proteins. The pocket validation is based on four different methods like prox4, prox 5.5, fpocket, and DoGSite. http://pockdrug.rpbs. univ-paris-diderot.fr/cgi-bin/index.py?page=home.

\section{Result and Discussion}

\section{Homology Modeling}

Protein (Novel Corona-Virus Spike Receptor-Binding Domain Complexes with Its Receptor ACE2) has two chains: chain-A (Angiotensin-converting enzyme2) and Chain-B (Spike glycoprotein) with ligands $1 \times N A G, 1 \times Z N$. Models are built based on the target-template alignment using ProMod3 (Li 2016). As shown in Fig. 1, the homology modeling is carried out via $\mathrm{X}$-ray diffraction method with a resolution value 2.50A0. This complements the GMQE score $(0.99)$ which estimates the accuracy of the tertiary structure of the model. The QMEAN score is -0.45 . It has torsion value as -0.89 and 0.47 as salvation (Malik et al. 2020).

SARS-CoV-2 NSP10/NSP16 Methyl-transferase in a Complex with SAM has two chains: chain $\mathrm{A}\left(2^{\prime}-O-\right.$ methyltransferase) Chain B (Non-structural protein 10) including ligands $1 \times 8 \mathrm{nk}$ (7-methylguanosine 5 '-diphosphate), $1 \times$ gta (p1-7-methylguanosine-p3-adenosine-5',5'triphosphate), $1 \times \operatorname{sah}($ s-adenosyl-1-homocysteine), $2 \times \mathrm{zn}$ (zinc ion) model was built via $\mathrm{X}$-ray diffraction with resolution power 2.10A0 it has QSQE score 0.91 which estimates the accuracy GMQE with sore 0.97.the QMEAN score is -1.35 . Torsion and Solvation of the residue are -0.60 and - 1.82 respectively (Maurya et al. 2020). (QSQE: Quaternary Structure Quality Estimate, GMQE: Global Model Quality Estimation, QMEAN: Quality Model Analysis).
Fig. 1 The figure demonstrates homology models (Swiss Model); a Spike glycoprotein with ACE2 Receptor and $\mathbf{b}$ Nsp10/Nsp16 methyl transferase

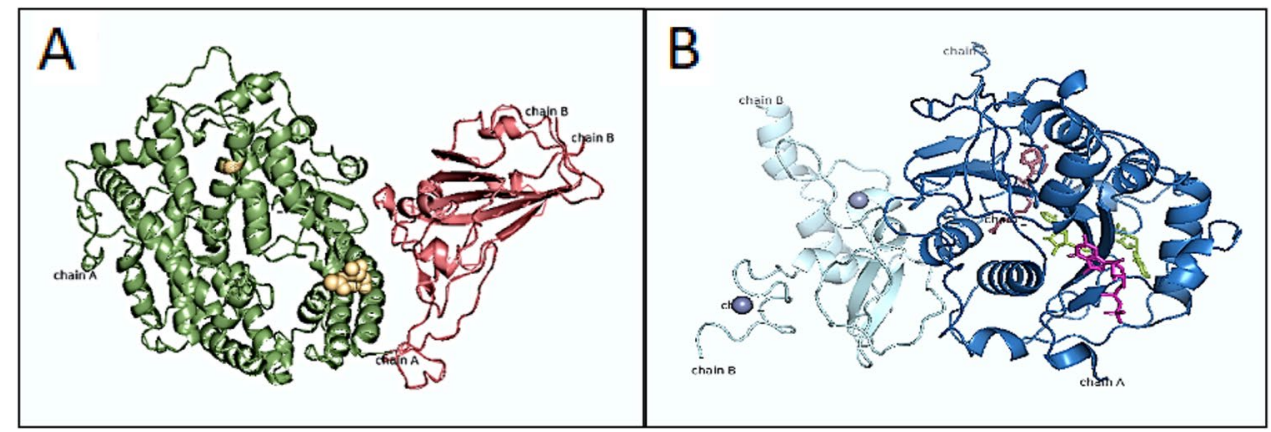




\section{Binding Free Energy Properties of Ligand-Receptor}

MM/GBSA is employed using HAWKDOCK to predict the binding free energy.MM-GBSA (Molecular mechanicsGeneralized Born Model and Solvent Accessibility) we approached computational method to calculate the absolute binding affinities between ligand and receptor (Millet and Whittaker 2018). Various features related to binding free energy like VdW: Vander Waal potentials, ELE: Electrostatic potentials, GB: Polar Solvation free energies are evaluated by the Generalized Born model, SA: Nonpolar contribution to the solvation free energy calculated by an empirical model, TOTAL: Final estimated binding free energy is $2.84 \mathrm{kcal} / \mathrm{mol}$ calculated from the terms above. (The lower binding free energy, the more critical residues) (Zhang et al. 2020; Mohan et al. 2021). Hence, the scoring depicts the structure is critical residue and sensible structure as a target. The given Fig. 2 shows the prediction of (MMGBSA) with binding free energy features and values. Top 5 binding affinities per residue in both receptor and ligand with their binding energies are as follows (Fig. 3):

- Residue (receptor): THR-679 (- 3.88), GLY-677 (2.29), THR-2 (- 1.99), ARG-564 (- 1.99), ASP691 ($1.63)$.
- Residue (ligand): MET-270 (- 3.59), VAL-400 (- 2.94), LYS-277 (-2.59), SER-273 (- 2.54), VAL-338 (- 2.46).

\section{Structural Prediction of Protein-Protein Interactions}

The protein-protein docking was performed on a real case from a CAPRI experiment using pydock. Finally, RMSD comparison with the real 3-D complex structure will be given to check the results of our "simulated CAPRI experiment". The result tabular form analyzes for protein-protein interactions of structure (Ni et al. 2020). The docking poses are visualized using PYMOL (Fig. 4, Table 1).

\section{Structural Prediction of Macromolecular Docking}

Given two individual structures i.e. Spike receptor binding domain with its ACE2 receptor submitted as receptor and NSP10/NSP16 as Ligand (Panda et al. 2020). The predicted binding mode possesses an acceptable accuracy according to the CAPRI criteria. The top performed binding sites of receptor and ligand using HDOCK are predicted (Fig. 5). The dashboard also describes the summary of top-5

Fig. 2 The figure demonstrates structure of MM-GBSA

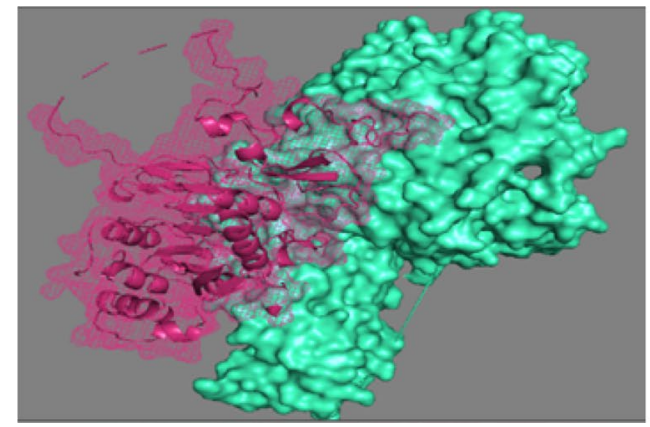

\begin{tabular}{|l|c|}
\hline RESIDUE_ID & $\begin{array}{c}\text { Ligand- } \\
\text { Receptor }\end{array}$ \\
\hline VDW & -117.75 \\
\hline ELE & -343.52 \\
\hline GB & 479.17 \\
\hline SA & -15.06 \\
\hline TOTAL & $\mathbf{2 . 8 4} \mathbf{k c a l} / \mathbf{m o l}$ \\
\hline
\end{tabular}

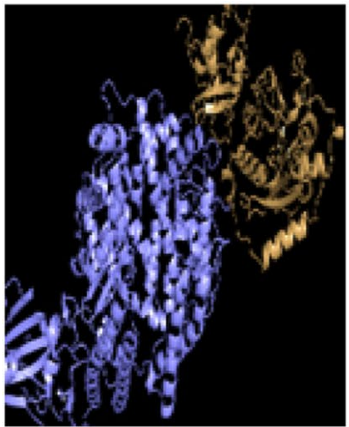

Model 1

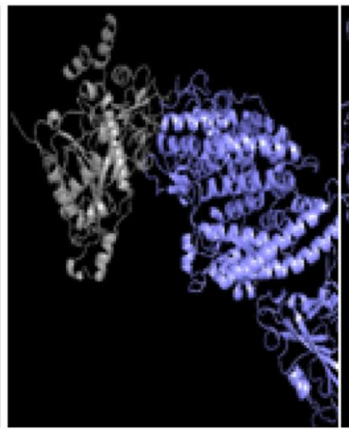

Model 2

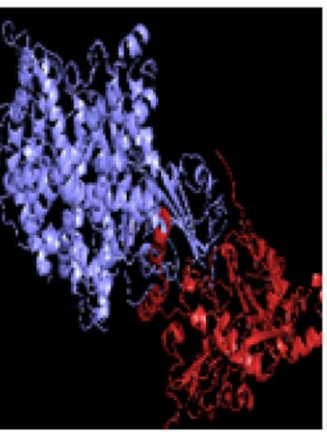

Model 3

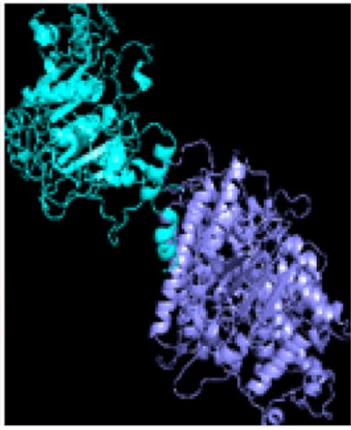

Model 4

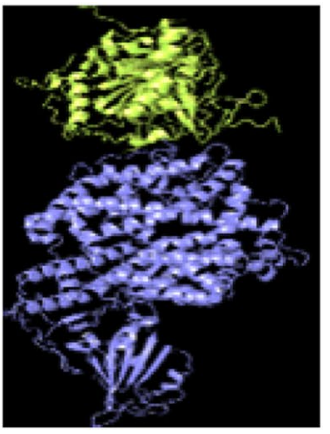

Model 5

Fig. 3 The structural prediction of protein-protein interactions using pydock. Receptor: purple in colour. Ligand: sand, greyish, red, teal green, lime in colour. The dash board shows the five different structural interactions with receptor and ligand (Color figure online) 


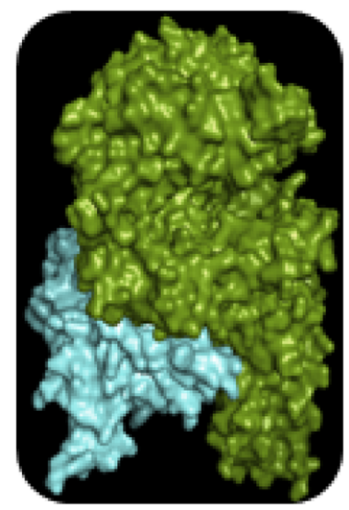

Model 1

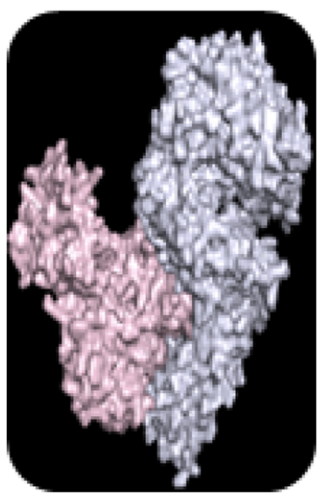

Model 2

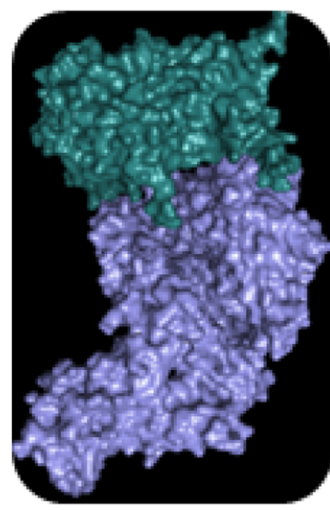

Model 3

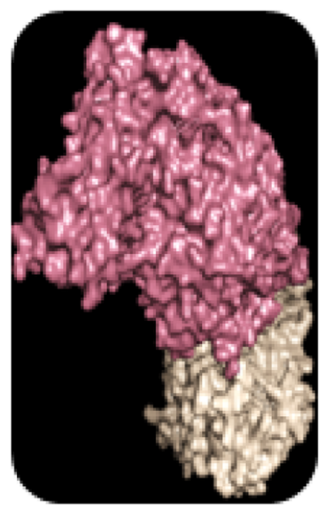

Model 4

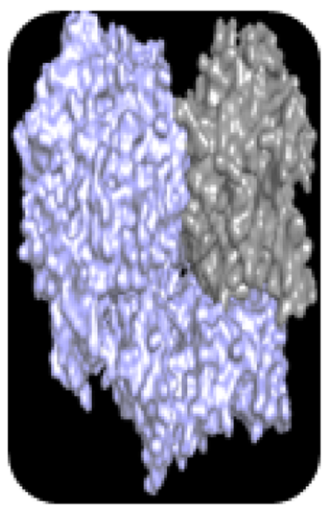

Model 5

\begin{tabular}{|c|c|c|c|c|c|}
\hline RANK & $\mathbf{1}$ & $\mathbf{2}$ & $\mathbf{3}$ & $\mathbf{4}$ & $\mathbf{5}$ \\
\hline Docking score & -286.92 & -254.11 & -239.67 & -238.59 & -234.63 \\
\hline Ligand RMSD(A $^{\circ}$ ) & 89.46 & 85.61 & 135.67 & 139.49 & 91.49 \\
\hline
\end{tabular}

Fig. 4 The figure show the top 5 dockable conformations with -286.92 score and 89.46 as the acceptable and accurate binding pose

Table 1 The tabular form depicts top 5 ranks, 2 .

Ele, 3. Desolv, 4. VdW,

5. Total binding energy

$($ Ele + Desolv $+0.1 * \mathrm{VDW})$

\begin{tabular}{lllcc}
\hline Rank & $\begin{array}{l}\text { Electrostatic energy } \\
(\mathrm{kCal} / \mathrm{mol})\end{array}$ & $\begin{array}{l}\text { Desolvation energy } \\
(\mathrm{kCal} / \mathrm{mol})\end{array}$ & $\begin{array}{l}\text { Vdw energy } \\
(\mathrm{kCal} / \mathrm{mol})\end{array}$ & $\begin{array}{c}\text { Total bind- } \\
\text { ing energy } \\
(\mathrm{kCal} / \mathrm{mol})\end{array}$ \\
\hline 1 & -11.428 & -28.493 & 17.614 & -38.160 \\
2 & -23.599 & -13.787 & -4.124 & -37.798 \\
3 & -24.937 & -8.263 & -44.541 & -37.655 \\
4 & -5.807 & -33.198 & 16.888 & -37.317 \\
5 & -17.716 & -22.142 & 37.509 & -36.107 \\
\hline
\end{tabular}

models of docked structures i.e., binding modes of receptor and Ligand (Weng et al. 2019). (Row-1: Rank of the top 5 docked models, Row-2: Docking score, Row-3: Ligand RMSD of modeled structures using homologous templates (Phan 2020). Moreover, a quality report of the docking structure is also given as shown in Fig. 4: Quality report of receptor: LG score: 5.322(very good) Maxsub: 0.377(good) and Quality report of ligand: LG score: 4.664 (good) Maxsub: 0.356 (good). Thusly, the census of receptor and ligand docking poses are cohesive with good quality report which is a consequence of stable complex when bound to each other with complementarity (Porter et al. 2019; Weng et al. 2020).

\section{Binding Site Prediction}

Drug ability, the target identification is major aspect of drug discovery. We have predicted the ability of protein pocket to bind with high affinity as a drug candidate Pock Drug. It is efficient for receptor and ligand as well which are estimated pockets using several thresholds (Pallara et al. 2017). It scrutinizes various intermolecular interactions with scoring potential like volume of the whole structure, hydrophobicity, polar residues, Aromatic residues, otyr atom, and number of residue (Sharma et al. 2020; Singhal 2020). The structures are put down in hierarchy according to their peak drug capability model. The descriptors are Volume of convex hull (Å3, Vol. hull), Hydrophobicity based properties of residues (Hydroph), Polar residues, Aromatic residues, Otyr atom (Toor et al. 2020), Number of pocket residues (Nb Res), Drug Probability, Standard deviation. Therefore, pocket drug ability investigations represent a key step of compound clinical progression projects (Waterhouse et al. 2018). Earlier, Verma and Shakya (2021), shown binding affinity of receptor and Ligand are function of binding pose (Table 2).

Post translational modification is essential step in the flow of genetic information. Several proteins and enzyme remain associated with post translational modification of host RNA and vital RNA as well. Viruses mainly RNA viruses evolved with several enzymes including 2-O-MTase allow an mRNA modification to bypass 


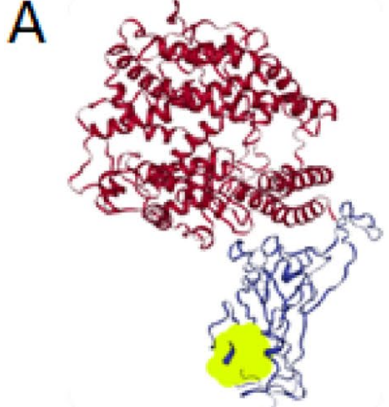

Model 1

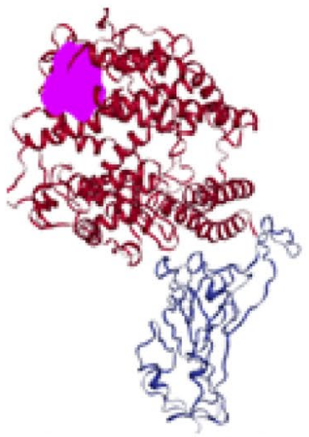

Model 2

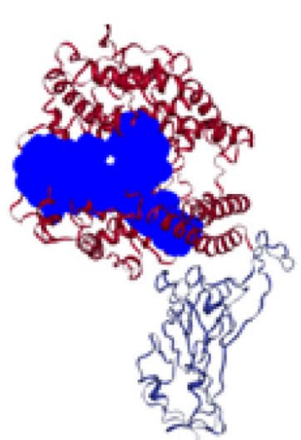

Model 3

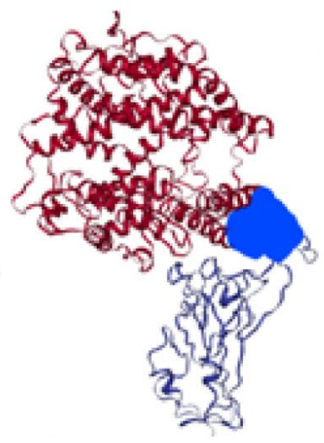

Model 4

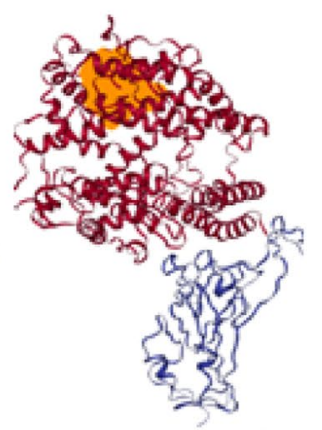

Model 5

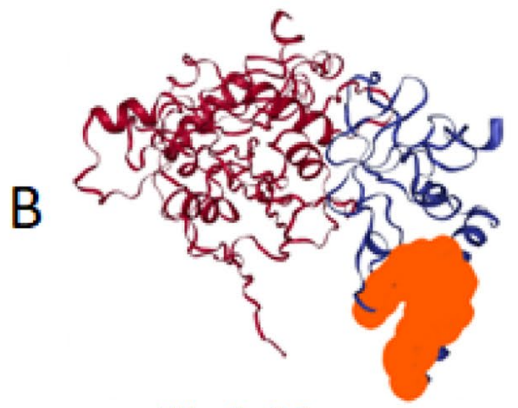

Model 1
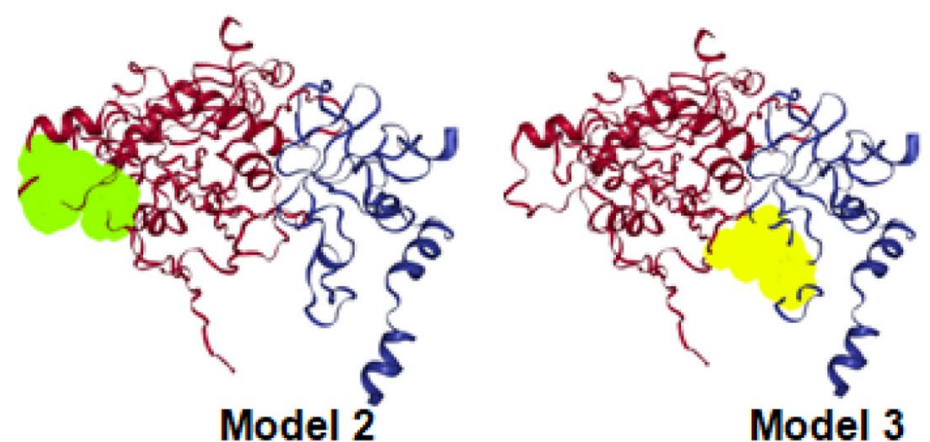

Model 3

Fig. 5 Figure demonstrates druggble sites a the top binding sites of the receptor (spike glycoprotein) are given in above 5models. The colour lime green, lavender, blue, blue, and orange respectively depict the estimated druggable sites in the receptor protein, of SARS
CoV-2 using Pock Drug. b The given structures with colour orange, green, and yellow are estimated as druggable sites in ligand protein structure(nsp10/nsp16) (Color figure online)

Table 2 Evaluates the intermolecular properties scoring concerning the drug ability between receptor and ligand of the top-5 highest scoring druggable models using Pock Drug

\begin{tabular}{|c|c|c|c|c|c|c|c|c|}
\hline Pockets (receptor) & Vol. hull & Hydroph & Polar Res & Aromatic Res & Otyr atom & $\mathrm{Nb}$ Res & $\begin{array}{l}\text { Drug prob- } \\
\text { ability }\end{array}$ & Stand dev \\
\hline Model 1 & 554.05 & 0.83 & 0.4 & 0.07 & 0.03 & 15.0 & 0.96 & 0.02 \\
\hline Model 2 & 527.35 & 1.31 & 0.47 & 0.33 & 0.0 & 12.0 & 0.99 & 0.0 \\
\hline Model 3 & 790.76 & -0.46 & 0.6 & 0.4 & 0.05 & 15.0 & 0.87 & 0.02 \\
\hline Model 4 & $12,195.9$ & -1.26 & 0.69 & 0.28 & 0.02 & 68.0 & 0.67 & 0.08 \\
\hline Model 5 & 815.8 & -0.91 & 0.54 & 0.29 & 0.02 & 14.0 & 0.52 & 0.05 \\
\hline $\begin{array}{l}\text { Pockets } \\
\text { (ligand) }\end{array}$ & Vol. hull & Hydroph & Polar Res & Aromatic Res & Otyr atom & $\mathrm{Nb}$ Res & $\begin{array}{l}\text { Drug prob- } \\
\text { ability }\end{array}$ & Stand dev \\
\hline Model 1 & 948.18 & 0.48 & 0.47 & 0.13 & 0.02 & 15.0 & 0.94 & 0.01 \\
\hline Model 2 & 682.88 & 0.4 & 0.43 & 0.07 & 0.03 & 14.0 & 0.89 & 0.04 \\
\hline Model 3 & 526.23 & 0.09 & 0.64 & 0.29 & 0.0 & 14.0 & 0.89 & 0.06 \\
\hline
\end{tabular}

host immune surveillance. Decroly et al. demonstrated that SARS CoV-2 Nsp16 activated via Nsp10 utilizing 2 '-O-MTase activity. The previous finding also suggests that $2^{\prime}-O$-MTase activity remain associated with other viruses as well such as mouse hepatitis virus (MHV) (Krafcikova et al. 2020). The Nsp10/16 MTase activity is critical for viral genome replication and evasion against immune surveillance. The present study was aimed to target Nsp10/16 MTase activity to restrict viral genome replication and as ease in recognize by host immune machinery. Nsp10 here serve as co factor for MTase activity in conjugation with Nsp16. Hence, targeting Nsp10/16 MTase 
could result in potential antiviral drug including against nSARS-CoV-2 (Wang et al. 2015; Krafcikova et al. 2020).

\section{Conclusion}

The fundamental role of the spike protein in infectivity indicates that it is a major target for immunogenic development. The stimulation of Nsp16 methyltransferase activity by Nsp10 may be a common mechanism for Coronaviruses. Our study results have implications for design and discover specific anticorona viral medicine to regulate the virus infection. The present study describes docking poses, MMGBSA, binding sites and drug ability that is aimed towards molecular associations certain to infection and replication. Therefore, these findings would help to control the exploiting pandemic condition. Thus the receptor and ligand form a stable complex according to the quality report of docked poses. A major try can turn out prospering medicine and vaccinations against prevailing and potential future SARS-CoV-2 infections to reduce the tremendous impact on human life.

Acknowledgements The author would like to acknowledge Department of Biotechnology, Acharya Nagarjuna University, Guntur, Andhra Pradesh, India for kind support and providing a facility for proposed study.

\section{Compliance with Ethical Standards}

Conflict of interest The authors declare no conflict of interest.

\section{References}

Ahmad J, Ikram S, Ahmad F, Rehman IU, Mushtaq M (2020) SARSCoV-2 RNA Dependent RNA polymerase (RdRp) - a drug repurposing study. Heliyon 6(7):e04502

Alazmi M, Motwalli O (2020) Molecular basis for drug repurposing to study the interface of the S protein in SARS-CoV-2 and human ACE2 through docking, characterization, and molecular dynamics for natural drug candidates. J Mol Model 26(12):338

Albini A, Di Guardo G, Noonan DM, Lombardo M (2020) The SARSCoV-2 receptor, ACE-2, is expressed on many different cell types: implications for ACE-inhibitor- and angiotensin II receptor blocker-based cardiovascular therapies. Intern Emerg Med 15(5):759-766

Baig AM, Khaleeq A, Ali U, Syeda H (2020) Evidence of the COVID19 virus targeting the CNS: tissue distribution, host-virus interaction, and proposed neurotropic mechanisms. ACS Chem Neurosci 11(7):995-998

Bello M (2020) Prediction of potential inhibitors of the dimeric SARS$\mathrm{CoV} 2$ main proteinase through the MM/GBSA approach. J Mol Graph Model 101:107762

Chellapandi P, Saranya S (2020) Genomics insights of SARS-CoV-2 (COVID-19) into target-based drug discovery. Med Chem Res. https://doi.org/10.1007/s00044-020-02610-8

Chen N, Zhou M, Dong X, Qu J, Gong F, Han Y et al (2020) Epidemiological and clinical characteristics of 99 cases of 2019 novel coronavirus pneumonia in Wuhan, China: a descriptive study". Lancet 395(10223):507-513

Choudhary S, Malik YS, Tomar S (2020) Identification of SARSCoV-2 cell entry inhibitors by drug repurposing using in silico structure-based virtual screening approach. Front Immunol $11: 1664$

Davidson AM et al (2020) Interaction of SARS-CoV-2 and other coronavirus with ACE (angiotensin-converting enzyme)- 2 as their main receptor: therapeutic implications. Hypertension (Dallas, Tex.; 1979) 76(5):1339-1349

Donoghue M, Hsieh F, Baronas E, Godbout K, Gosselin M, Stagliano $\mathrm{N}$ et al (2020) A novel angiotensin-converting enzyme-related carboxypeptidase (ACE2) converts angiotensin I to angiotensin 1-9. Circ Res 87(5):E1-9

El Hassab MA, Shoun AA, Al-Rashood ST, Al-Warhi T, Eldehna WM (2020) Identification of a new potential SARS-COV-2 RNAdependent RNA polymerase inhibitor via combining fragmentbased drug design, docking, molecular dynamics, and MM-PBSA calculations. Front Chem 8:584894

Gorbalenya AE, Baker SC, Baric RS, de Groot RJ, Drosten C, Gulyaeva AA et al (2020) The species severe acute respiratory syndrome-related coronavirus: classifying 2019-nCoV and naming it SARS-CoV-2". Nat Microbiol 5(4):536-544

Guo YR, Cao QD, Hong ZS, Tan YY, Chen SD, Jin HJ, Tan KS, Wang DY, Yan Y (2020) The origin, transmission and clinical therapies on coronavirus disease 2019 (COVID-19) outbreak-an update on the status. Mil Med Res 7(1):11

Hamming I, Timens W, Bulthuis ML, Lely AT, Navis G, van Goor H (2004) Tissue distribution of ACE2 protein, the functional receptor for SARS coronavirus. A first step in understanding SARS pathogenesis. J Pathol 203(2):631-637

Hoffman M, Kliene-Weber H, Kruger N, Herrler T, Erichsen S, Schiergens TS et al (2020) SARS-CoV-2 cell entry depends on ACE2 and TMPRSS 2 and is blocked by a clinically proven protease inhibitor. Cell 181(2):271-280.e8

Hussein HA, Borrel A, Geneix C, Petitjean M, Regad L, Camproux AC (2015) PockDrug-server: a new web server for predicting pocket druggability on holo and apo proteins. Nucleic Acids Res 43(W1):W436-W442

Kaswa R, Govender I (2004) Novel coronavirus pandemic: a clinical overview. S Afr Fam Pract 62(1):e1-e5. https://doi.org/10.4102/ safp.v62i1.5123

Krafcikova P, Silhan J, Nencka R et al (2020) Structural analysis of the SARS-CoV-2 methyltransferase complex involved in RNA cap creation bound to sinefungin. Nat Commun 11:3717. https://doi. org/10.1038/s41467-020-17495-9

Krishnan DA, Sangeetha G, Vajravijayan S, Nandhagopal N, Gunasekaran K (2020) Structure-based drug designing towards the identification of potential anti-viral for COVID-19 by targeting endoribonuclease NSP15. Inf Med Unlocked 20:100392

Lai CC, Shih TP, Ko WC, Tang HJ, Hsueh PR (2020) Severe acute respiratory syndrome coronavirus 2 (SARS-CoV-2) and coronavirus disease-2019 (COVID-19): the epidemic and the challenges. Int J Antimicrob Agents 55(3):105924. https://doi.org/10.1016/j.ijant imicag.2020.105924

Letko M, Marzi A, Munster V (2020) Functional assessment of cell entry and receptor usage for SARS-CoV-2 and other lineage B beta-coronaviruses. Nat Microbiol 5(4):562-569

Li F (2016) Structure, function, and evolution of coronavirus spike proteins. Ann Rev Virol 31:237-261

Li F, Li W, Farzan M, Harrison SC (2005) Structure of SARS coronavirus spike receptor-binding domain complexed with receptor. Science 309(5742):1864-1868

Li Y, Zhou W, Yang L, You R (2020) Physiological and pathological regulation of ACE2, the SARS-CoV-2 receptor. Pharmacol Res 157:104833. https://doi.org/10.1016/j.phrs.2020.104833 
Malik YS, Kumar N, Sircar S, Kaushik R, Bhat S, Dhama K et al (2020) Coronavirus disease pandemic (COVID-19): challenges and a global perspective. Pathogens 9(7):519

Maurya VK, Kumar S, Prasad AK, Bhatt MLB, Saxena SK (2020) Structure-based drug designing for potential antiviral activity of selected natural products from ayurveda against SARS-CoV-2 spike glycoprotein and its cellular receptor. Virus Dis 31(2):179193. https://doi.org/10.1007/s13337-020-00598-8

Millet JK, Whittaker GR (2018) Physiological and molecular triggers for SARS-CoV membrane fusion and entry into host cells. Virology 517:3-8

Mohan SV, Hemalatha M, Kopperi H, Ranjith I, Kumar AK (2021) SARS-CoV-2 in environmental perspective: occurrence, persistence, surveillance, inactivation and challenges. Chem Eng J 405:126893

Ni W, Yang X, Yang D, Bao J, Li R, Xiao Y, Hou C et al (2020) Role of angiotensin-converting enzyme 2 (ACE2) in COVID-19. Crit Care 24(1):422

Pallara C, Jiménez-García B, Romero M, Moal IH, Fernández-Recio J (2017) pyDock scoring for the new modeling challenges in docking: protein-peptide, homo-multimers, and domain-domain interactions. Proteins 85(3):487-496

Panda PK, Arul MN, Patel P, Verma SK (2020) Structure-based drug designing and immunoinformatics approach for SARS-CoV-2. Sci Adv 6(28):eabb097

Phan T (2020) Genetic diversity and evolution of SARS-CoV-2. Infect Genet Evol 81:104260. https://doi.org/10.1016/j.meegid.2020. 104260

Porter KA et al (2019) What method to use for protein-protein docking? Curr Opin Struct Biol 59:1-7

Sharma A, Tiwari S, Deb MK, Marty JL (2020) Severe acute respiratory syndrome coronavirus-2 (SARS-CoV-2): a global pandemic and treatment strategies. Int J Antimicrob Agents 56(2): 106054

Singhal T (2020) A review of coronavirus disease-2019 (COVID-19). Indian J Pediatr 87(4):281-286

Toor HG, Banerjee DI, Lipsa Rath S, Darji SA (2020) Computational drug re-purposing targeting the spike glycoprotein of SARSCoV-2 as an effective strategy to neutralize COVID-19. Eur J Pharmacol 890:173720
Verma MK, Shakya S (2020) Genetic variation in chemokines receptor 5 gene and course of HIV infection; review on genetics and immunological aspect. Gene Dis. https://doi.org/10.1016/j.gendis. 2020.04.007

Verma MK, Shakya S (2021) LRP-1 mediated endocytosis of EFE across the blood-brain barrier protein-protein interaction and molecular dynamics analysis. Int J Pept Res Ther 27:71-81. https://doi.org/10.1007/s10989-020-10065-Z

Wang Y, Sun Y, Wu A, Xu S, Pan R, Zeng C, Jin X, Ge X, Shi Z, Ahola T, Chen Y, Guo D (2015) Coronavirus nsp10/nsp16 methyltransferase can be targeted by nsp10-derived peptide in vitro and in vivo to reduce replication and pathogenesis. J Virol 89:84168427. https://doi.org/10.1128/JVI.00948-15

Waterhouse A, Bertoni M, Bienert S, Studer G, Tauriello G, Gumienny R (2018) SWISS-MODEL: homology modelling of protein structures and complexes. Nucleic Acids Res 46(W1):W296-W303

Weng G, Wang E, Wang Z, Liu H, Zhu F, Li D, Hou T (2019) HawkDock: a web server to predict and analyze the protein-protein complex based on computational docking and MM/GBSA. Nucleic Acids Res 47(W1):W322-W330

Weng G, Gao J, Wang Z, Wang E, Hu X, Yao X, Cao D, Hou T (2020) Comprehensive evaluation of fourteen docking programs on protein-peptide complexes. J Chem Theory Comput 16(6):3959-3969

Xu X, Chen P, Wang J, Feng J, Zhou H, Li X et al (2020) Evolution of the novel coronavirus from the ongoing Wuhan outbreak and modeling of its spike protein for risk of human transmission. Sci China Life Sci 63(3):457-460

Zhang XY, Huang HJ, Zhuang DL, Nasser MI, Yang MH, Zhu P, Zhao MY (2020) Biological, clinical and epidemiological features of COVID-19, SARS and MERS and AutoDock simulation of ACE2. Infect Dis Poverty 9(1):99

Publisher's Note Springer Nature remains neutral with regard to jurisdictional claims in published maps and institutional affiliations. 